\title{
Body Mass Index, Physical Activity, Nutritional Habits, and Perceived Body Image Among Pacific Islanders in the Federated States of Micronesia 太平洋島居民的體質指數、身體活動、營養攝取及身體形象
}

\author{
Kelle L. MURPHY \\ School of Education, \\ University of Guam, GUAM \\ 艾尼梅菲 \\ 關島大學教育學院

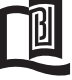

\begin{abstract}
The purpose of the study was to examine the physical activity levels, nutrition, and body image of participants from Yap Proper and the outer islands. A mixed methods design was utilized. Participants included 29 adults enrolled in an undergraduate Education degree program from two separate summer school classes: 19 adults from an Introductory Health and Wellness class and 12 adults from a PE Methods: Elementary class for classroom teachers. Three higher-order themes resulted from the analysis: Cultural Values, Body Image, and Westernization. Results from the nutrition logs indicated that participants preferred local grown foods and also consumed western imported foods available on the island. Daily step counts of participants ranged from a low of 190 steps on day one to a high of 12,375 on day 28. By day 28, participants were walking between 3-6 miles per day. Additional exercise outside of walking was not performed by participants. The mean of Pre-BMI data were 31.91 and the mean for Post-BMI data were 31.97. Participants stated that they felt that their bodies were fat and that they were satisfied with that image. Participants also indicated that a higher importance in their culture was placed on obesity and that an obese body was associated with beauty and prosperity. Findings suggest that cultural beliefs contribute to obesity rates by affecting the type of physical activity that is performed due to gender-specific roles. Lack of access to a variety of nutritious foods also affects nutrition habits.
\end{abstract}

Key Words: physical activity, nutrition, body mass index, Micronesians, Outer Islands

\section{摘 要}

本文旨在探討太平洋島居民的體質指數、身體活動、營養攝取及身體形象。結果顯示文化因素是影響身體肥胖的原因。

\section{Introduction}

Overweight and obesity have become a nation-wide health concern (Becker, Gilman, \& Burwell, 2005; Cassels, 2006; Mhurchu, Rodgers, Pan, Gu, \& Woodward, 2004). Obesity is defined as "individuals with a high percent of body fat, generally over $25 \%$ for men and over $30 \%$ for women" (Powers, Dodd, \& Noland, 2006). Typically, Body Mass Index (BMI) is the measure used to determine obesity and is the ratio of height to weight (Powers et al., 2006). Overweight is defined as a BMI value between 25-29 (Powers et al., 2006). Obesity has become a concern because of the implications for Americans' health. 
Since the mid-seventies, the prevalence of overweight and obesity has increased sharply for both adults and children. Data from two National Health and Nutrition Examination surveys (Overweight \& Obesity, 2007) show that among adults aged 20-74 years the prevalence of obesity increased from $15.0 \%$ (in the 1976-1980 survey) to $32.9 \%$ (in the 2003-2004 survey). Results of the surveys reveal that being overweight or obese increases the risk of many diseases and health conditions, including the following: hypertension; dyslipidemia (for example, high total cholesterol or high levels of triglycerides); type 2 diabetes; coronary heart disease; stroke; gallbladder disease; osteoarthritis; sleep apnea and respiratory problems; and some cancers (endometrial, breast, and colon).

Due to Western influence, obesity related health concerns have slowly become prevalent in the Asia-Pacific region which includes Islands of Micronesia, Guam, the Commonwealth of the Northern Mariana Islands (CNMI), Cook Islands, and Western Samoa (Becker et al., Brownstein, 2007; 2005; Cassels, 2006; Mhurchu et al., 2004). A number of researchers have examined BMI among Pacific Islanders (Chiem et al., 2006; Mhurchu et al., 2004; Pelletier \& Rahn, 2007), food and nutrition (Englberger et al., 2003), westernization and changing lifestyles (Cassels, 2006; Englberger et al., 2003), changes in overweight and obesity (Calindas, 2007; Becker et al., 2005; Streib, 2007), cardiovascular disease and chronic disease (Mhurchu et al., 2004) and body image (McDowell $\&$ Bond, 2006). Of particular concern are the pacific islanders of Micronesia. The name Micronesia means "little islands" and consists of thousands of islands in the West Pacific and is in-between Hawaii and the Philippines (Levy, 2003). The Federated States of Micronesia (FSM) is the largest and most populated and includes: the Caroline Islands, Pohnpei, Kosrae, Chuuk, and Yap (Levy, 2003). FSM has been rated in the top five for in the world's fattest countries (Brownstein, 2007; Calindas, 2007; Streib, 2007). According to Cassels (2006), Micronesia is "one of the most, if not the most, overweight populations in the world.” (p. 2).

Typically, Micronesian islanders depended on local grown food and used "man power" to harvest the food; however, with the Western influence, came a reliance on salty foods, canned foods, fatty meats and less of a dependence on local man power (Cassells, 2006; Englberger et al., 2003). Modernization also introduced the television and conveniences that are less labor intensive and have contributed to an increase in inactivity. Physical manual labor has decreased as a result (Calindas, 2007; Cassells, 2006; Englberger et al., 2003).

Additional contributing factors are cultural beliefs regarding body image. Sociocultural and religious beliefs guide attitudes pertaining to eating and body image among Pacific Islanders (McDowell \& Bond, 2006). The belief is that a large body is sign of beauty and wealth (McDowell \& Bond, 2006; Streib, 2007). Those who are of large frames are doing well economically and can afford to buy more food.

Few if any researchers have sought to understand body image, physical activity, and nutrition among outer islanders. The purpose of this study was to examine the physical activity levels, nutrition, and body image of participants from Yap Proper and the outer islands. The outer islands are those islands that are included within the Micronesian region.

\section{Research Questions}

The following research questions were examined within the context of the study: Research Question \# 1: What are the mean body mass index values for male and female Pacific Islanders? ; Research Question \# 2: What are the mean daily step counts for male and female Pacific Islanders? ; Research Question \# 3: What are the daily nutritional habits among male and female Pacific Islanders? ; and Research Question \# 4: How does the perception of body image differ among male and female Pacific Islanders?

\section{Methods}

A mixed methods design (Creswell, 1994) was utilized in this study. Within this design both qualitative and quantitative methods were used (Creswell, 1994). The qualitative design was used to answer the questions posed for this study because of its descriptive nature, concern with process rather than product, natural setting, and the construction of a reality that is holistic and multiple (Creswell, 2000; Lincoln \& Guba, 1985). The quantitative design was used to collect numerical data to add support for the findings of the research questions. 


\section{Participants}

Participants included 31 adults from two separate summer school classes: 19 adults from an Introductory Health and Wellness class and 12 adults from a PE Methods: Elementary class for classroom teachers. The summer session was conducted for 28 days. All participants were enrolled in an undergraduate degree program in Education and were taking the courses as requirements for the degree. The majority of participants were from the outer islands of Yap Proper. Two participants did not participate due to illness on the day of the focus groups. Total participants included 29 ( $\underline{\mathrm{N}}=$ 29). Participants consisted of: classroom teachers $(\underline{n}=25)$; principals $(\underline{\mathrm{n}}=3$; two high school and one elementary); and an administrator $(\underline{n}=1)$. Breakdown by gender included 25 males and 4 females. Academic majors included: Elementary Education $(\underline{\mathrm{n}}=27)$ and Secondary Education $(\underline{n}=2)$. Participants taught all subjects and all grade levels. Average age of participants was 50 years. Age ranged from 40-59 years. Average years of teaching were 22 years. Years of teaching experience ranged from 5-37. The purpose and procedures were explained on the first day of classes and informed consent was signed by all participants. Pseudonyms were assigned to all participants to ensure anonymity and confidentiality along with an identification number that would allow information to be traced back to the original participant by both researchers.

\section{Data Collection}

\section{Focus Groups and Questioning Route}

Each participant took part in one focus group that lasted an average of 1hour. A total of four focus groups were conducted and were divided by gender: three focus groups for males and one focus group for females. Focus groups were videotaped and audiotaped. One researcher (the instructor of the class) transcribed the audiotapes verbatim and observed the videotapes which were used to supplement and add clarification and support to the transcribed notes.

Focus groups were conducted at the end of the third week of classes. This was done to allow participants to become comfortable with each other and the researcher which would allow for more open communication to occur during the focus groups. Procedures were explained to all participants prior to beginning of each focus group. Questions for the focus groups were reviewed and participants were given time to ask questions for clarification. All focus groups were conducted by one researcher who served as the instructor for both classes.

A multiple-category design according to Krueger and Casey (2000) was utilized for the focus groups. Guidelines provided by Krueger and Casey (2000) were followed for the questioning route. Good questions consist of those that are conversational, clear, short, one dimensional, openended, and progress from general to specific (Krueger \& Casey, 2000). The questioning route is presented in Table 1. Questions were used to elicit information regarding daily physical activity, nutritional habits, and perceptions of body image among males and females.

Table 1. Questioning Route Pertaining to Physical Activity and Nutritional Habits and Perceived Body Image Among Male and Female Pacific Islanders $(\underline{N}=29)$.

1. State your name and why you are taking this class.

2. What types of body image are accepted on this island?

3. What types of body images do you feel are more acceptable and why?

4. What types of physical activities are acceptable to participate in?

5. Why are those types more acceptable than others?

6. What types of physical activities are more acceptable for males to participate in and why?

7. What types of physical activities are more acceptable for females to participate in and why?

8. How does it make you feel when you see people working out?

9. What types of foods do you prefer to eat?

10. Can you explain the nutritional value of the food you eat?

11. The purpose of this was for us to understand body image, nutrition, and physical activity patterns on the island. Is there anything that we missed? Is there anything that you did not have a chance to say that you would like to add at this point? 


\section{Exercise and Nutrition Logs}

Participants maintained a daily $\log$ of exercise and nutrition habits. Participants were asked to record the type of food eaten, the amount, and the time of day when food was consumed. They also recorded the type

\section{Table 2. Example of exercise and nutrition logs.}

\section{Exercise Log}

Directions: Record the type of exercise, the distance or duration, and the time of day exercise was performed.

Type of Exercise

\section{Distance}

Time of Day

\section{$\bar{\Gamma}$ \\ Nutrition Log}

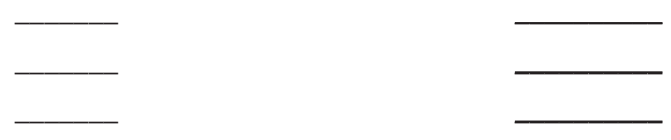

Directions: Record the food eaten, the amount, and the time of day when food was consumed.

Food Eaten

Amount

Time of Day of exercise, the distance or duration, and the time of day exercise was performed. All exercise and nutrition logs were collected on the final day of classes. An example of the exercise and nutrition $\log$ is presented in Table 2.

\section{Laboratory Exercises}

Participants completed selected laboratory assignments from the assigned textbook for the course that pertained specifically to perceived body image. Labs were chosen and assigned by the instructor and were collected on the days that they were completed by participants.

\section{Daily Pedometer Step Counts}

On the first day of classes, all participants were assigned a pedometer, given an explanation and demonstration of how to properly wear and use the devices, and were asked to wear it and record daily step counts on a rubric Rubrics containing daily step counts were created by the instructor and were collected on the final day of classes. An example of a step count rubric is presented in Table 3.

\section{Table 3. Example of daily step count rubric.}

Directions: Put on the pedometer in the morning once you are ready to begin the day and wear it all day until you are ready for bed. Record the total number of steps each day.

Date

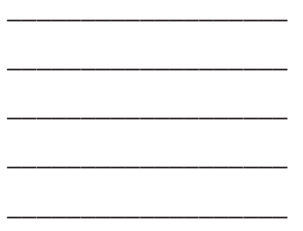

Total Number of Steps

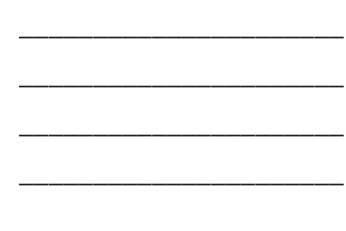

Daily step counts of participants ranged from a low of 190 on day one to a high of 12,374 on day 28.

*2,000 steps is equal to about one mile and 10,000 steps is equal to about 5 miles (www.thewalkingsite.com) 


\section{Pre- and Post-BMI Measurements}

Participants provided Body Mass Index (BMI) on two occasions: once on the first day of classes and again on the final day of classes. The instructor provided a scale and tape measure and recorded height and weight of each participant. The instructor then computed BMI by inserting the values into a computer program which determined the BMI values.

\section{PAR-Q}

All participants completed the Physical Activity Readiness Questionnaire (PAR-Q) prior to volunteering to participate in the study and prior to signing informed consent. The questionnaire assesses physical activity readiness and determines whether or not a doctor's recommendation is needed to participate in physical activity.

\section{Data Analysis}

A mixed methods design (Creswell, 1994) was employed in this study. Qualitative data were coded over three phases. Means of quantitative data (BMI and daily pedometer readings) were used to supplement and add support for the findings of qualitative data. Data collected from daily nutrition logs and various laboratory assignments completed in class were also used to add support for the findings.

Data analysis followed the same process as an earlier study conducted by Murphy (2007). Qualitative data analysis occurred simultaneously with data collection by both researchers (Thomas, Nelson, \& Silverman, 2005). Data were analyzed inductively and deductively according to the procedures outlined by Gould, Finch, and Jackson (1993). A constant comparison method was used (Glaser \& Strauss, 1967). Audiotapes were transcribed verbatim and checked by the researcher for accuracy. Data contained line numbers that could be traced back to the participant by the researcher. Coding of data occurred over several phases and was performed by two researchers. The second researcher served as a peer debriefer and assisted in the coding process. The researcher was chosen due to her experience in qualitative research.

During the initial phase of coding, each researcher independently combed data several times identifying references to daily physical activity and nutritional habits and perception of body image that related directly to the research questions. Exact quotes were cut out and treated as individual raw data units (Gould et al., 1993). Concept maps were developed at this point as a technique to visualize the connections among raw data themes (Maxwell, 1996). Raw data units were cut and placed on poster boards to create the concept maps. Raw data units were first inductively analyzed and categorized into meaningful lower-order themes. Lower-order themes were represented by three to four words that served as descriptors of the overall meanings of raw data units (Gould et al., 1993). Individual raw data units were placed under multiple lower-order themes. Researchers reviewed coding to reach agreement of lower-order themes assigned to raw data units. Raw data units were placed in separate lower-order themes until a consensus was met as to descriptor given to the lower-order theme. This process continued until all possible lower-order themes were exhausted. When a consensus was not met, researchers discussed alternative descriptors for lower-order themes until a consensus was met.

During the second phase of coding, lower-order themes were combed multiple times by both researchers and inductively analyzed and categorized into meaningful higher-order themes (Gould et al., 1993). Higher-order themes were represented by three to four words that served as descriptors of the overall meanings of lowerorder themes (Gould et al., 1993). Higher-order themes that were assigned different descriptors were placed in separate higher-order themes until a consensus was met as to descriptor given to the higher-order themes. This process continued until all possible higher-order themes were exhausted. When a consensus was not met, researchers discussed alternative descriptors for higher-order themes until a consensus was met.

\section{Trustworthiness}

Analysis of trustworthiness followed the same process as an earlier study conducted by Murphy (2007). Lincoln and Guba (1985) discuss four criteria to determine the trustworthiness of a study: credibility, transferability, dependability, and confirmability. Thomas et al. (2005) offer examples of evidence of trustworthiness of a study that include: prolonged engagement, audit trail, rich, thick description, clarification of researcher bias, triangulation, negative case checking, and member checking. Trustworthiness was provided in the current study by the following: (a) audit trail, by the use of written notes, transcribed notes, videotapes, synthesis of 
data through concept maps, and process notes (Lincoln \& Guba, 1985); (b) in-depth description of participants and the setting (c) triangulation, by the use of multiple researchers and multiple forms of data collection; and (f) purposeful selection of participants to fit criteria of study and maintaining anonymity and confidentially (Lincoln \& Guba, 1985).

\section{Results}

The purpose of this study was to examine the physical activity levels, nutrition habits, and body image of participants from Yap Proper and the outer islands. Results from the nutrition logs indicated that participants continued to consume local grown foods such as taro, breadfruit, and bananas, turtle, fish, and chicken and also consumed western imported foods that were available on the island such as rice, hamburger, corned beef and canned meat. Based on a stride length of 2.5 feet, it takes about 2,000 steps to equal one mile and 10,000 steps is close to 5 miles (www.thewalkingsite.com). The daily step count of participants ranged from the lowest of 190 steps on day one to the highest of 12, 374 steps on day 28 (Table 3). The average walked by participants by the end of the study was between 3-6 miles per day. Participants engaged in walking during class and used walking as their mode of transportation around the island. They progressed from a sedentary lifestyle on day one to engaging in regular physical activity by day 28 . Additional exercise beyond walking was not performed by participants. The mean of Pre-BMI data were 31.91 and the mean for Post-BMI data were 31.97 (Table 4). Participants wrote in various laboratory exercises that they felt that their bodies were fat and that they were satisfied with that image. Participants also indicated that a higher importance in their culture was placed on obesity and that an obese body was associated with beauty and prosperity. Qualitative analysis resulted in a total of 311 raw data units. These raw data units were condensed into five lower-order themes, which were further condensed into three higher-order themes. Lower-order themes and higher-order themes are presented in Figure 1. Results have been presented by lower-order themes and higherorder themes.

Table 4. Body Mass Index values pretest and posttest $\underline{\mathbf{N}}=29$.

\begin{tabular}{|c|c|c|c|}
\hline Student & Pre-BMI & Post-BMI & Island \\
\hline $\begin{array}{l}1 \\
2 \\
3 \\
4 \\
5 \\
6 \\
7 \\
8 \\
9 \\
10 \\
11 \\
12 \\
13 \\
14 \\
15 \\
16 \\
17 \\
18 \\
19 \\
20 \\
21 \\
22 \\
23 \\
24 \\
25 \\
26 \\
27 \\
28 \\
29\end{array}$ & $\begin{array}{l}40.1 \\
30.4 \\
29.6 \\
31.0 \\
39.8 \\
29.7 \\
29.2 \\
30.0 \\
39.2 \\
36.2 \\
34.7 \\
30.4 \\
27.5 \\
29.2 \\
26.7 \\
33.4 \\
31.9 \\
32.4 \\
30.6 \\
37.3 \\
29.4 \\
28.5 \\
33.6 \\
31.1 \\
29.9 \\
30.2 \\
29.1 \\
39.3 \\
25.1 \\
\text { M = } 31.91\end{array}$ & $\begin{array}{l}39.0 \\
30.6 \\
30.8 \\
29.6 \\
40.6 \\
30.2 \\
29.4 \\
30.5 \\
38.2 \\
36.9 \\
36.0 \\
30.6 \\
26.5 \\
28.9 \\
26.6 \\
33.2 \\
30.8 \\
32.4 \\
30.6 \\
37.3 \\
28.3 \\
28.7 \\
33.6 \\
30.8 \\
30.5 \\
30.6 \\
31.3 \\
38.9 \\
25.9 \\
\text { M = } 31.97\end{array}$ & $\begin{array}{l}\text { Falalop Ulithi } \\
\text { Elato Atoll } \\
\text { Lamotrek Atoll } \\
\text { Fatharaii Island } \\
\text { Asor, Ulithi } \\
\text { Tegailap, Woleai } \\
\text { Satawal } \\
\text { Falalop Ulithi } \\
\text { Satawal } \\
\text { Satawal } \\
\text { Wottagai Woleai } \\
\text { Satawal } \\
\text { Ifalik atoll } \\
\text { Ifalik Atoll } \\
\text { Satawal } \\
\text { Falalop, Wleai } \\
\text { Yap Island } \\
\text { Ifealic } \\
\text { Yap, Tomil } \\
\text { Falalop, Ulithi } \\
\text { Falalop, Wleai } \\
\text { Fais Island } \\
\text { Mogmog, Ulithi } \\
\text { Mogmog, Ulithi } \\
\text { Satawal } \\
\text { Wottegai, Wleai } \\
\text { Lamotrek Atoll } \\
\text { Lamotrek Atoll } \\
\text { Falalop, Woleai }\end{array}$ \\
\hline
\end{tabular}




\section{Figure 1. Concept map depicting higher-order and lower-order themes.}

\section{Lower-order Themes}

Commercialization

Educational Influence

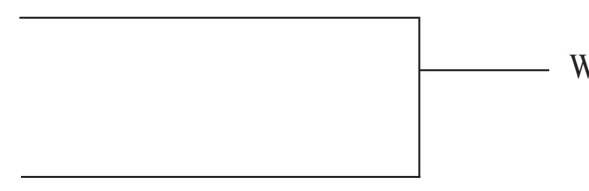

Cultural Beliefs

Local Food

Man Power

Authors Note: Thank you to Dr. Catherine Stoicovy for her contributions.

\section{Westernization}

The two lower-order themes of commercialization and educational influence were condensed into the higher-order theme of westernization. The theme of westernization was characterized by the influences and traditions of the western culture that were introduced and adopted by the participants of the outer islands and Yap Proper.

Commercialization. Commercialization was defined as the products imported to the islands from the Mainland U.S. These products represented modernization and convenience for the islanders. Edmond explained the convenience brought by commercialization by stating:

because we are working most of the time, we tend to go to the store and buy canned meat or credit canned meat to eat for lunch or dinner...and like rice is now popular food especially for workers because it is much quicker to cook. You just get it out of the store and pour it in a pot and wash it and cook it. Instead of going through the jungle or to the taro patch or far away places to harvest the local produce.
Westernization

Body Image

\section{Higher-order Themes}

\section{Cultural Values}


The introduction of jobs changed the lifestyles of the islanders and provided less time to harvest food from the land. Edmond explained "we don't have time to do our fishing or gardening, so we just fish in the store (everyone laughing in agreement)." As a result, children ate the canned foods because the parents were working and not at home preparing the meals. When explaining that the children rely on canned food, Justine stated "they don't have any choice because they come home and their parents are at work. They all come together and they fix the fast food or junk (Lucia nodding in agreement).

The taste of the canned food and imported western food was preferred to the local food. This had an impact on the amount of local food that was consumed. Not only did the canned western food add more convenience to their lifestyles, but it also brought a variety in taste. Adding spices for additional taste was not a part of the preparation of local foods. Stanis explained his children's preferences for the western food by stating: "so when my kids come home and they taste the food and they know it's my food so they leave it (Thadius smiling in agreement)." Franklin stated in agreement:

these youngsters, they do understand the importance of our local food; however, they want to eat this imported food from outside. They like rice, corned beef and some other canned meat better than our locally made food. These youngsters do understand the importance of our food, but I know they like the western food much better than ours.

A generation gap was found for the preference to western canned food. The older generation who was more accustomed to the local food, preferred the local food to the western canned food. A preferred taste for the western food was not easily acquired by the older generation. Stanis explained this by stating:

but me, I'm looking for the wild yams and they have banana, papaya, then can cook for me. They never add anything to it with ingredients. They just cook papaya with only water. And the fish, they don't add any salt or any salt in the water.

The younger generation became more accustomed to the convenience and taste of the western canned food and as a result preferred it to the local food. In opposition, the older generation preferred the locally grown food.
Even with the knowledge of the lack of nutritional value of the canned western food, taste and convenience was a dominant reason of why it was preferred and consumed.

Interestingly, the older generation held the belief that the canned food imported to the island was poisonous and not good for consumption. Samuel explained "we've learned from our textbooks and other people, foreigners that in the stores what you will get from the stores are canned foods that are containing so many kinds of diseases or sickness." In comparison to the local food, Lucia stated "poison, these chemicals that preserve the food, but the local food is fresh. Just get it and cook it, and eat it (Cecelia nodding in agreement). This belief may have contributed to the older generation's reluctance to eat the western food.

Educational influence. Along with westernization also came an increase in educational influence which resulted in an increase in information regarding healthy lifestyles. Westernization introduced formal education. Islanders are given the opportunity to pursue educational degrees. Many have to leave the island for months at a time to study. As a result, they gain information regarding other cultures and learn how to prevent chronic diseases and illnesses. While explaining the impact of education on the lifestyles of islanders, Justine stated:

a long time ago, there was, we don't see people walking by or like jogging or biking (Evarsita nodding in agreement). But two or three years ago, just recently we saw people walking or some jogging or some biking. And to me when I look at them doing that, I know that they are doing it for a purpose. Either they are doing it for health or fitness. It's good for them.

Samuel stated in agreement "but now I understand that when you work out you make yourself fit and healthy so you can stay longer than you're expecting to." Once islanders learned the importance of proper nutrition and exercise, they began to teach the concepts to their children in the island schools. One participant explained "we teach that in the schools and we tell the kids to stay with the balanced meal." Thadius also stated "we teach the kids to work out and to have a healthy body (Stanis nodding in agreement). Knowledge and information gained through these experiences and opportunities can positively impact lifestyle changes that can be passed on to generations. 


\section{Cultural Values}

Participants possessed traditional cultural values regarding nutrition and exercise that were in opposition to the beliefs of the western culture. The three lower-order themes of cultural beliefs, local food, and man power were condensed into the higher-order theme of cultural values.

Cultural beliefs. A generation gap was found with regard to beliefs regarding the importance of exercise. The younger generation is being exposed to the importance of exercise in the schools. Participants learned about the benefits of a wellness lifestyle and the connection to a decrease in the occurrence of chronic diseases in the courses that they enrolled in. When asked if there were generational differences regarding the beliefs in exercise, the response was that the older generation viewed exercise as nonsense and a waste of time. This may have been due to a lack of information regarding the health benefits of exercise. The older generation believed that the type of exercise that should be performed should be related to performing work. In reference to performance of physical activity related to wellness, Edmond stated: "when we get older and we walk, they (elders) say hey what are you doing? Are you crazy? We have other things that we can do aside but are still exercising like building canoes. You do all the days work." Moses further explained "these older people seeing these young people work out, they think that this is a waste of time because they don't understand that you work out to make yourself fit." For the older generation on the island working out was accepted if it was specifically related to work. The concept of a wellness lifestyle was not understood.

Man Power. Most activities on the islands related to work were labor intensive. Participants used the words man power to refer to exercise that was received when performing work related activities. This was exercise embedded in work activities. When defining this, Samuel explained "as we jump from the canoe or boat and we swim from there maybe five miles catching fish, spearing fish for us-that is exercise. The lady, a woman can go to the taro patch and spend four hours tearing the taro from the taro patch. For us, we think of that as exercise." When speaking about collecting firewood, Evarsita stated "but we don't consider that exercise, we just say okay lets go get the firewood (Juliana stating yes in agreement). Lorenzo agreed stating "we look at it as the activities that we do back home as some sort of exercise even though they are not the same as what the Western people do, what they exercise." The islanders performed labor intensive activities that they considered to be exercise, rather than aerobic activities that Westerners would engage in.

As one of the assignments of the class, participants were asked to keep daily exercise logs. Participants first learned the concepts of target heart rate, were introduced to the use of pedometers, and engaged in daily stretching and walking at the beginning of each class. Participants did state that initially they felt sore and did not like stretching and walking. Towards the end of the course, they stated that they enjoyed the walking because they felt revived afterwards and also stated that they were able to walk longer distances, keeping within target heart range by the completion of the course. By participating in these activities, participants did learn the importance of exercise and understood the benefits. They also were able to distinguish the differences between the exercises performed in class compared to the exercises engaged in on their islands. Based on an average stride length of 2.5 feet, about 2,000 steps is close to one mile and 10,000 steps is close to 5 miles (www.thewalkingsite.com). Step counts ranged from the lowest of 190 on day one to the highest of 12,374 on day 28. By the end of the class, participants were walking an average of 3-6 miles per day. A sedentary person averages between 1,0003,000 steps per day (www.thewalkingsite.com). Outside of class, participants did not engage in any other physical activities other than walking. Many did not have cars and therefore, had to walk to go to various places. Clearly participants progressed from a sedentary lifestyle on day one to engaging in daily activity by day 28 .

Participants held specific cultural beliefs regarding gender-specific activities. Richard explained "on my island, physical activities that are acceptable for men are picking breadfruit, cutting tuba, sailing and building canoes. And on the women's part- planting, gardening and preparing food (Sesariyo nodding in agreement)." There were strong cultural beliefs regarding men and women. Women were considered lower than men and in that case, were not supposed to engage in activities that would place them physically higher then men. Moses offered an example by stating "women are not supposed to be doing activities that involve climbing and such activities as you know going up where they'll be above the male." Due to those beliefs, men and women performed very tradition genderspecific activities. 
Local Food. In terms of the nutritional value of foods and eating daily balanced meals, participants were limited to the food available on the island and what was imported to the islands. Vegetables, fruits, and proteins were available on the island. The food that is harvested on the island is seasonal and not available year round. When referring to the local food grown on the island, Lucia stated "we only have the banana, breadfruit, and taro. It's hard to grow foods on our islands. The taro, breadfruit, and banana already grow out there. But these different kinds of food that this people here have, we don't have." Robert and Moses stated in agreement "our islands are very small and we don't have any choice. It's like if we have taro to eat today, eat taro. If you have bananas, that's what we eat. Mostly fish. We don't have much choice." Moses stated in agreement "the greens that are also good for the health are very limited on the islands."

While attending classes on Yap Proper, participants did have more of a choice in the types of foods that could be consumed. Many preferred local grown foods because that is what they were accustomed to eating. As an activity in the class, participants were asked to keep daily nutrition logs. In the logs, participants wrote that they continued to consume local foods such as taro, breadfruit, and bananas, turtle, fish, and chicken but also consumed Western imported foods that were available on the island such as rice, hamburger, corned beef and canned meat. The imported foods were only available on the islands when the ship brought them in and were only available for a limited time. These imported foods were not necessarily more nutritious. Most were high in salt and saturated fats which added to an unhealthy diet.

\section{Body Image}

The higher-order theme of body image stood alone and represented a conflict between westernization and traditional cultural beliefs. Gender differences were not found. Males and females held the same perception of body image. Participants intellectually understood a wellness lifestyle. Through their coursework and reading books, they learned the importance of daily physical activity, proper nutrition and balanced meals. They understood the connection between obesity, cardiovascular disease, diabetes, and other chronic illnesses. Despite this knowledge, cultural values placed a higher importance on obesity and associated an obese body with beauty and prosperity. While explaining such beliefs, Samuel stated "they prefer to see someone who is obese and the think of that as well off. The person might have a lot of food. The person is well off." Samuel further explained "we can marry to a lady who is obese and the lady has more food. Then we can survive then being married to a slim one." Lucia stated in agreement "And those that are too skinny they sometimes feel sorry for them because they think that they don't have enough food and they work too much."

Weight was also associated with whether or not a person was viewed as healthy. Edmond agreed stating that "according to our custom, when you look fat, you look healthy." Males prefer heavy women and found this trait to be more attractive. Thadius explained in agreement "females are supposed to be big, big, fat. I think that they look pretty that way. A skinny woman may not be too attractive (Jerome smiling and nodding in agreement)." Similarly, Richard stated "in terms of choosing a husband or wife, they prefer more the type of people that they call in the category of endomorph (everyone smiling in agreement). An endomorphic body is defined as one that is round and fat.

A generation gap was found between these two beliefs. The younger culture has experienced more western influence and has had the opportunity to learn various chronic diseases and illnesses commonly associated with overweight and obesity. The older generation associates overweight and obesity with being healthier. Samuel explained the generational differences by stating:

if I were to go out and start physical education, the young mother and young father might accept it, but the older parents, they will look at me and say I don't want you to put my child in that class. They prefer to see a chubby kid.

One of the laboratory exercises completed during a class pertained to assessing body image. The answers written by participants reinforced the above beliefs. Most participants wrote that they felt their bodies were fat and were satisfied with that image. Participants did indicate that this image was not a healthy one. Edmond wrote "I heard from friends and learned that the ideal body are those in shape. Fat people lead to heart problems and other diseases.' This was learned through taking courses and being exposed to educational materials. In spite of this acquired knowledge, cultural beliefs were reinforced. 
Body mass index (BMI) of participants also supported the cultural belief of overweight and obese as being more attracted and accepted. Body Mass Index is the ratio of weight to height and is a gauge for whether a person is considered underweight, normal weight, overweight, or obese (Powers et al., 2006). A person who has a BMI value raging from 25-29.9 is considered overweight (Powers et al., 2006). A person who has a BMI value that is 30 or greater is considered obese (Powers et al., 2006). Body Mass Index was taken for participants on two occasions: once on the first day and once on the last day. The average BMI value at pretest was 31.91 and the average BMI value at posttest was 31.97. Out of 29 participants on the first day, 11 had BMI values that were in the overweight range and 18 had BMI values in the obese range. None had underweight or normal range BMI values. Post-test values indicated an increase in BMI values in the obese range. At posttest, 9 participants had BMI values in the overweight range and 20 had BMI values in the obese range. The increase in the BMI values at posttest was due to an increase in consumption of imported foods available on Yap Proper. Rice and canned meat were in abundance and consumed more often by participants because it was not available as often on the outer islands. Moses reiterated:

some people might think that ah coming here to Yap proper will change the story but ah if I show people my diet log, they will think that the problem is worse here then on my island. And that is not because I do not ah, we do not have ah the type of food that I like on my island, here. It is also true here because when we are here, we still do not have a choice because we eat only whatever we can afford from the store.

The food that participants could afford was not necessarily the most nutritious. Canned meat was eaten by many participants and also was very high in sodium and saturated fats. Rice when eaten in abundance is high in calories.

In summary, it was found that participants performed labor intensive activities as a part of daily work activities and did not participate in daily aerobic exercises that sustained a target heart rate for an extended period of time. Proper nutrition and balanced meals was lacking due to the availability of foods on the island. Limited types of fruits, vegetables, and proteins were available, but the food grown on the island was seasonal. Foods such as rice and canned meats that were imported to the islands were not as nutritious. Body mass index values of participants were in the overweight and obese range. This supported the cultural belief that the ideal body image was that of a heavy, round, obese person.

\section{Limitations}

When interpreting the results of the current study, limitations should be considered. All participants were from the outer islands, which allowed for certain assumptions to be made by them. As is typical of case studies, the purposive sampling procedure decreases the generalizability of findings. This study will not be generalized to all Yap islanders. Participants were participating in a course directly related to the research questions. The knowledge gained by them may have influenced their answers. The presence of the Chief in one of the male focus group may have influenced the responses of participants in that particular focus groups. Chiefs are highest in the social hierarchy and many participants may have felt reluctant to be forthcoming with answers. Additionally, the biases of the researchers and those interviewed may influence the interpretations of findings.

\section{Discussions}

The purpose of this study was to examine the physical activity levels, nutrition, and body image of participants from Yap Proper and the outer islands. The outer islands are those islands that are included within the Micronesian region. Overall, the BMI values remained in the obese range from pretest to posttest. Three reasons can contribute to this outcome: food consumption, cultural beliefs, and length of class. First, Proper nutrition and balanced meals was limited to what was available on the islands. They did have a small selection of fruits, vegetables, and proteins available. Foods that were imported to the islands were not as nutritional as the fruits and vegetables. Participants consumed more western foods that were available to them on Yap Proper. These foods included canned meats that were high in sodium and fat, but participants ate these foods because they were available and they liked the taste. Second, cultural beliefs included a higher importance on obesity. Obesity in their culture was associated with beauty and prosperity. Participants wrote in various laboratory exercises that they felt that their bodies were fat and that they were satisfied with that image. This belief was reiterated in the 
focus groups by many participants. Third, the class was only one month long and not long enough to experience any significant changes. Participants did progress from a sedentary lifestyle on day one to participating in daily activity and walking 3-6 miles by day 28. Part of this was due to the fact that daily walking was a requirement of the class. Participants walked at the beginning of each class. Many participants did not drive and therefore, had to walk as their main mode of transportation.

Five lower-order themes emerged that were condensed into three higher-order themes. The three lower-order themes of commercialization, and educational influence were condensed into the higher-order theme of westernization. The three lower-order themes of cultural beliefs, local food, and man power were condensed into the higher-order theme of cultural values. The higher order theme of body image stood alone and represented a conflict between the higher order themes of westernization and cultural values. Discussion will be presented by higher-order themes. The results of the current study are consistent with findings in pedagogical research.

\section{Westernization}

The higher-order theme of westernization is defined as the influences that were brought to the islands by the western culture. These influences were in the form of commercialization, information and knowledge, educational influence. Participants learned to enjoy the conveniences and benefits of western culture that were brought to the island. Imported foods such as rice and canned meat are imported to the island after typhoons and storms. Local island food is prepared with no additives. Canned foods contained salt, which is a taste preferred by the islanders. The imported foods are not necessarily more nutritious, but are easier and faster to prepare. After working all day, it is a preference to have food that is faster to prepare. These findings are in agreement with Hodge, Dowse, Koki, Mavo, Alpers, and Zimmet (1995) and Hodge, Dowse, Zimmet, and Collins (1995) who found that "modernization is associated with increased consumption of salted and processed foods and animal foods higher in saturated fats, and decreased consumption of complex carbohydrates" (p. 2). The islanders are dependent on foreign aid especially after typhoons. This dependency resulted in a change in preference of foods (Cassels, 2006).
Similarly, Cassels (2006) stated that "a combination of dietary change influenced by foreigners, dependence on foreign aid, and the ease of global food trade contributed to poor diet and increased rates of obesity in Micronesia" (p. 2). Participants in the current study all held Body Mass Index values that are in the overweight and obese range. The number of participants categorized in the obese range increased by poststudy. This is due to the increase in consumption of salty foods and meats higher in saturated fats. There is an increase in availability of such foods on Yap Proper. Participants took advantage of this and consumed more while visiting the island. According to Cassels (2006), foods such as turkey tails that have been deemed inedible in the mainland U.S are a popular imported food in the Federated States of Micronesia (FSM).

A shift in local lifestyle has contributed to the increase in obesity among islanders (Cassels, 2006; Englberger et al., 2003). These finding are also in agreement with findings of the World Health Organization, stating that "overweight is increasingly prevalent in developed and developing populations" (p. 1). With the influences of mondernization, there is less of a need for labor intensive work. Participants choose to be more sedentary and consume foods higher in salts and saturated fats which result in weight gain.

\section{Body Image}

In the current study, the higher-order theme of body image represented a conflict between the higher-order themes of westernization and cultural values. Cultural beliefs reinforce the ideal body as one that is round, heavy, and obese. The finding of the current study is in agreement with the findings of Streib (2007) who reported that "the common belief that beauty is marked by a large physical size, the reliance on fatty, nutrientdeficient imported foods, and a decrease in activity caused by less farming and agricultural work" has contributed to an increase in obesity that is beginning to occur in some developing areas in the Pacific region (p. 4). Due to the increase reliance on fatty imported foods, participants in the current study report performing less manual labor. This change has contributed to a more inactive lifestyle. Similarly, McDowell and Bond (2006) also found that "a large body has been traditionally highly valued" (p. 1). This belief contributes to the inability to make lifestyle changes that are healthier. 
An interesting finding the current study related to cultural beliefs is the belief that food is related to wealth. A person who is heavy and has a lot of food is considered well-off and is held in higher esteem among community members. McDowell \& Bond (2006) and Strieb (2007) also found that large frames are a sign of economic wealth. For the participants, this view was realistic and guided their beliefs and behaviors. Participants intellectually learned what was entailed in a healthy lifestyle, but cultural beliefs dominated how they actually reacted.

Gender differences were not found for body image. Males and females hold the same cultural beliefs regarding body image, and intellectually understand that the culture beliefs represent an image that is less healthy and more susceptible to chronic diseases. This finding could have been due to a power differential that may have been present in the current study (Krueger \& Casey, 2000). Focus groups were separated by gender, but there were Chiefs of various villages in the class were mixed into the focus groups due to the researcher not being aware of the hierarchy that existed. The presence of the Chief in the focus group may have contributed to the other members of the group not freely expressing opinions in fear of stating beliefs in opposition of the Chief.

\section{Cultural Values}

Cultural values and beliefs are very strong for participants and ultimately impact whether or not lifestyle changes towards a wellness lifestyle will occur. Participants hold very traditional values in terms of roles for males and females on the islands. Gender-specific activities are performed by participants. Females perform activities that have to do with the keeping of the home and include housework and gardening. Males perform the manual labor that is work related. Even though participants are exposed to different lifestyles through their educational opportunities, they hold strong to cultural values and beliefs.

A generation gap was found in regards to the belief of the importance of exercise. The average age of participants was 50 and included a more traditional group. The participants explained that the elders on the islands viewed exercise as nonsense and did not understand the health benefits. Even though these participants have been exposed to the benefits through their educational experiences, they were an older group who are influenced by the beliefs of the elders. They did express feeling the benefits of the walking by the end of the class and did express the importance of teaching the wellness lifestyle concepts to their children.

\section{Conclusion}

The findings of the current study have important implications for educators. Many researchers have examined nutrition and BMI values of Pacific Islanders; however, the participants in the current study were from the outer islands of Yap Proper and these islands have not been studied. Gaining an understanding of the cultural values and beliefs of participants first and understanding lifestyles is critical to being able to introduce any type of positive change. Change can then be introduced in a way that is not in opposition to any beliefs and should be slow and gradual. Change cannot occur if it is forced or has a negative impact on cultural values and beliefs.

\section{References}

Becker, A. E., Gilman, S. E., \& Burwell, R. A. (2005). Changes in prevalence of overweight and in body image among Fijan women between 1989 and 1998. Obesity Research, 13(1), 110-117.

Brownstein, R. (2007). Off the TV, an anti-obesity campaign in the CNMI. The Gazette, 18(7), 1-5.

Calindas, M. (2007). 70 Percent of NMI adults are overweight.

Cassels, S. (2006). Overweight in the Pactifc: Links between foreign dependence, global food trade, and obesity in the Federated States of Micronesia. Globalization and Health, 2(10), 1-10.

Chiem, B., Nguyen, V., Wu, P. L., Ko, C. M., Cruz, C. M., Sadler, G. R. (2006). Risk factors among Chamorros. BMC Public Health, 6, 1-10.

Creswell, J. (1994). Research design. Qualitative and quantitative approaches. Thousand, Oaks, CA: Sage.

Department of Health and Human Services Centers for Disease Control and Prevention (2007). Overweight and Obesity. Retrieved December 31, 2007 from http://www.cdc.gov/nccdphp/dnpa/obesity/ http://www. thewalkingsite.com/10,000steps.html 
Englberger, L., Marks, G.C., \& Fitzgerald, M. H. (2003). Insights on food and nutrition in the Federated States of Micronesia: A review of the literature. Public Healthy Nutrition, 6(1), 15-17.

Glaser, B. G., \& Strauss, A. (1967). The discover of grounded theory: Strategies for qualitative research. Chicago, IL: Aldine.

Gould, D., Finch, L. M., \& Jackson, S. A. (1993). Coping strategies used by national champion figure skaters. Research Quarterly for Exercise and sport, 64(4), 453-468.

Hodge, A. M., Dowse, G. K., Koki, G., Mavo, B., Alpers, M. P., \& Zimmet, P. Z. (1995). Modernity and obesity in coastal and highland Papua New Guinea. International Journal of Obesity, 19, 154-161.

Hodge, A. M., Douse, G. K., Zimmet, P. Z, \& Collins, V. R. (1995). Prevalence and secular trends in obesity in Pacific Indian Ocean Island populations. Obesity Research, 3, 77-87.

Krueger, R. A., \& Casey, M.A. (2000). Focus groups $\left(3^{\text {rd }}\right.$ ed). A practical guide for applied research. Thousands Oaks, CA: Sage.

Levy, N. M. (2003). Micronesia. Emeryville (6 ${ }^{\text {th }}$ ed.). CA: Moon Handbooks.

Lincoln, Y. S., \& Guba, E. G. (1985). Naturalistic inquiry. Newbury Park, CA: Sage.

Maxwell, J. A. (1996). Qualitative research design: An interactive approach. Thousand Oaks, CA: Sage.

McDowell, A. J. \& Bond, M. J. (2006). Body image differences among Malay, Samoan, and Australian women. Asia Pacific Journal of Clinical Nutrition, 15(2), 201-207.

Murphy, K. L. (2007). Perceptions of the student teaching triad: An inquiry into safe teaching practices of student teachers. Micronesian Educator, 12, 61-80.
Pelletier, D. L., \& Rahn, M. (2007). Trends in body mass index in developing countries.

Powers, S.K., Dodd, S. L., \& Noland, V. J. (2006). Total fitness and wellenss $\left(4^{\text {th }}\right.$ ed.). San Francisco, CA: Pearson.

Streib, L. (2007). Waistlines keep expanding around the globe: Urbanization, Western ways adding to the world's weight problem.

Strieb, L. (2007). World's fattest countries.

World Health Organization. Asia Pacific Cohort Studies Collaboration. (2004). Body mass index and cardiovascular disease in the Asia-Pacific region: An overview of 33 cohorts involving 310000 participants. International Journal of Epidemology, 33, 751-758. Anthropometry. WHO Technical Report. Geneva: WHO.

Zimmerman, C. (2007). Area students weigh in with opinions on nutrition, obesity.

\section{Correspondence:}

Kelle L. Murphy

Assistant Professor of Physical Education

School of Education, University of Guam

UOG Station, Mangilao, GU 96923

Telephone: (671) 735-2413

Fax: (671) 734-3651 